\title{
Studi tentang olengan bebas dan tahanan total kapal model uji di Laboratorium Kepelautan
}

\author{
A study on free roll and total resistence of test model ship in Seamanship Laboratory \\ Alian Manas, KaWILARAng W.A.MASEnGI* dan HENRY J. KuMAJAS \\ Program Studi Pemanfaatan Sumberdaya Perikanan, Fakultas Perikanan dan Ilmu Kelautan, \\ Universitas Sam Ratulangi, Manado 95115
}

\begin{abstract}
The awareness of the importance of advance technology application in marine studies, especially in utilizing optimally fisheries resources using an adequate vessel is increasing. Therefore, this research was done to understand the effect of hull shape and trim on the total resistance of down-scaled models of two fiberglass boat (5 and 30 GT) in fishing ports of North Sulawesi. Methods in this research included measurement of boats' main dimension, drawing the hulls using pantograph, redraw the hulls using a computer application program, and build a model. The results showed that: (1) the stability of the 5 GT model is better than that of the 30 GT model; (2) The 5 GT model has greater total resistance as it has fair hull shape.
\end{abstract}

Keywords: fiberglass, stability, resistance, purse seiner, North Sulawesi

\begin{abstract}
ABSTRAK
Semakin disadari akan pentingnya penerapan teknologi yang lebih maju dalam mengkaji aspek kelautan, terutama dalam memanfaatkan sumberdaya perikanan secara optimal dengan menggunakan sarana yang memadai. Olehnya, penelitian ini dilakukan untuk mengetahui sejauh mana pengaruh bentuk dan perubahan trim kapal terhadap tahanan total dan kestabilan dua kapal model uji yang datanya diperoleh pada kapal fibreglass (5 dan 30 GT) yang berpangkalan di beberapa pelabuhan perikanan di Provinsi Sulawesi Utara. Metode penelitian yang digunakan antara lain: pengukuran utama dimensi kapal, penggambaran lambung kapal dengan teknik pantograf, dan penggambaran kembali lambung kapal dengan menggunakan aplikasi komputer. Hasil penelitian ini menunjukkan bahwa: (1) stabilitas dari kapal model 5 GT relatif lebih stabil dari pada 30 GT; (2) kapal model 5 GT memiliki nilai tahanan total lebih besar oleh karena bentuk bodi kapal dan lambung kapal yang berbentuk gemuk.
\end{abstract}

Kata-kata kunci: fibreglass, stabilitas, tahaan, kapal pukat cincin, Sulawesi Utara

\section{PENDAHULUAN}

Indonesia merupakan negara kepulauan yang memiliki sumberdaya perikanan yang sangat besar, namun hingga saat ini lebih dari $95 \%$ usaha perikanan laut di Indonesia merupakan usaha skala kecil yang disebut usaha perikanan tradisional; selanjutnya dinyatakan pula bahwa 90\% perahu atau kapal-kapal penangkapan ikan di Indonesia beroperasi di perairan pantai. Dalam usaha memanfaatkan sumberdaya perikanan dan untuk meningkatkan produksi perikanan khususnya di bidang penangkapan tak lepas dari alat utama dan alat bantu pada usaha pemanfaatan

\footnotetext{
*Penulis untuk penyuratan; email: sabanib@yahoo.com
}

sumber daya tersebut. Salah satu faktor penunjang yang sangat penting adalah kapal ikan.

Secara umum, kapal penangkap ikan merupakan modal yang sangat penting dalam bisnis perikanan tangkap (Masengi $d k k$., 2000). Kapal ikan merupakan salah satu faktor yang sangat penting di antara unit penangkapan ikan, karena kapal ikan pada umumnya menyerap modal besar pada usaha penangkapan ikan (Pasaribu, 1986). Kapal ikan adalah kapal yang digunakan dalam dunia perikanan baik dalam usaha penangkapan ikan, mengumpulkan sumberdaya perairan, pekerjaan penelitian, latihan, pengawasan dan lain sebagainya yang berhubungan dengan hal tersebut (Ayodhyoa, 1972). 
Kapal ikan merupakan salah satu faktor penting dalam suatu usaha penangkapan ikan di laut. Di lain pihak para pengrajin kapal biasanya tidak terlalu memikirkan akan kebutuhan mesin pendorong dan kestabilan kapal. Olehnya peneliti ingin melihat sejauh mana pengaruh bentuk dan perubahan trim kapal terhadap tahanan total dan kestabilan kapal model tes yang datanya diperoleh pada kapal yang berpangkalan di beberapa pelabuhan perikanan di Provinsi Sulawesi Utara. Sehingga hasil tersebut diharapkan dapat dijadikan dasar acuan bagi pengrajin kapal ikan dalam memproduksi kapal.

Penelitian ini bertujuan untuk: (1) mengukur beberapa bentuk kapal FRP (Fibreglass Reinforced Plastic); (2) mengukur dan mempelajari olengan bebas kapal ikan; (3) membuat grafik olengan bebas kapal ikan; (4) mengetahui pengaruh tahanan total kapal terhadap beberapa jenis kapal FRP.

\section{METODE PENELITIAN}

Penelitian ini dilakukan di tangki hidrodinamika untuk melakukan beberapa pengujian dan pengolahan data hasil penelitian dilakukan di Laboratorium Kepelautan Fakultas Perikanan dan Ilmu Kelautan dengan menggunakan aplikasi software DELFTShip. Penelitian ini berdasarkan metode deskriptif yaitu suatu metode dalam meneliti status suatu obyek pada masa sekarang dengan tujuan membuat gambaran secara sistematis, fenomena, membuat prediksi dan mendapatkan makna serta implikasi dari masalah yang sedang diselidiki. Dasar penelitian ini adalah studi kasus, yaitu penelitian yang digunakan dengan cara mempelajari kasus-kasus tertentu pada objek penelitian yang terbatas (Ariyanto, 1986).

Teknik pengumpulan data dilakukan melalui pengamatan dan pengukuran secara langsung di lapangan. Data hull-line berdasarkan pantograph kemudian digambarkan dan dianalisis menggunakan aplikasi software Free!Ship agar bisa langsung diperoleh dimensi teknis bentuk kapal seperti body-plane, butock-line dan water-line.

Untuk mendapatkan gambaran yang jelas tentang tahanan total kapal berdasarkan perlakuan, maka hasil-hasil pengamatan digambarkan ke dalam hubungan antara tahanan total kapal (sumbu ordinat) pada beberapa kecepatan sebagai bilangan Froude (sumbu absis). Sehingga data yang didapat dari tangki percobaan akan dianalisis dengan menggunakan beberapa rumus yang biasanya digunakan untuk hal tersebut seperti yang dikemukakan oleh Harvald (1992) adalah sebagai berikut:

di mana:

$$
F n=\frac{\mathrm{V}}{\sqrt{\mathrm{g} \cdot \mathrm{L}_{\mathrm{wl}}}}
$$

\section{HASIL DAN PEMBAHASAN}

\section{Dimensi utama kapal prototipe}

Hasil pengukuran dimensi utama yang diukur langsung dari lapangan dan perhitungan berbagai parameter kedua kapal prototipe ditampilkan pada Tabel 1. Hasil pengukuran dimensi utama kapal selanjutnya diolah dengan aplikasi Delftship untuk mendapatkan gambar linesplane kapal (Gbr. 1\&2). Hasil pengukuran dimensi utama pada kapal model meliputi Length Over All (LOA), Breadth (B), dan Depth (D), dan koefisien bentuk dapat dilihat dalam Tabel 2.

Tabel 1. Paramer utama kapal 30 GT dan 5 GT

\begin{tabular}{llll}
\hline No & \multicolumn{1}{c}{ Parameter } & 30 GT & \multicolumn{1}{c}{$5 \mathrm{GT}$} \\
\hline 1 & L & $25 \mathrm{~m}$ & $13.30 \mathrm{~m}$ \\
2 & $\mathrm{~B}$ & $5 \mathrm{~m}$ & $3 \mathrm{~m}$ \\
3 & $\mathrm{D}$ & 1.2 & 0.5 \\
4 & L/B & 5.0 & 4.43 \\
5 & B/D & 5.0 & 6.0 \\
6 & Displacement & $4.17 \mathrm{ton}$ & 3.09 ton \\
7 & Block Coefficient $(\mathrm{Cb})$ & 0.46 & 0.19 \\
8 & Prismatic coefficient (Cp) & 0.54 & 0.34 \\
9 & Vert. Prismatic coefficient (Cvp) & 0.71 & 0.34 \\
\hline
\end{tabular}

\begin{tabular}{llll}
\hline No & \multicolumn{1}{c}{ Parameter } & $30 \mathrm{GT}$ & \multicolumn{1}{c}{$5 \mathrm{GT}$} \\
\hline 10 & Longitudinal center of buoyancy (LCB) & $10.77 \mathrm{~m}$ & $6.27 \mathrm{~m}$ \\
11 & Vert. center of buoyancy (VCB) & $0.7 \mathrm{~m}$ & $0.37 \mathrm{~m}$ \\
12 & Length on waterline (Lwl) & $22.77 \mathrm{~m}$ & $11.83 \mathrm{~m}$ \\
13 & Beam on waterline (Bwl) & $4.73 \mathrm{~m}$ & $2.69 \mathrm{~m}$ \\
14 & Waterplane area & 79.94 & 21.85 \\
15 & Waterplane coefficient & 0.63 & 0.54 \\
16 & Stabilitas kapal melintang & $2.35 \mathrm{~m}$ & $9.66 \mathrm{~m}$ \\
17 & stabilitas memanjang kapal & $34.65 \mathrm{~m}$ & $15.81 \mathrm{~m}$ \\
& & & \\
\hline
\end{tabular}




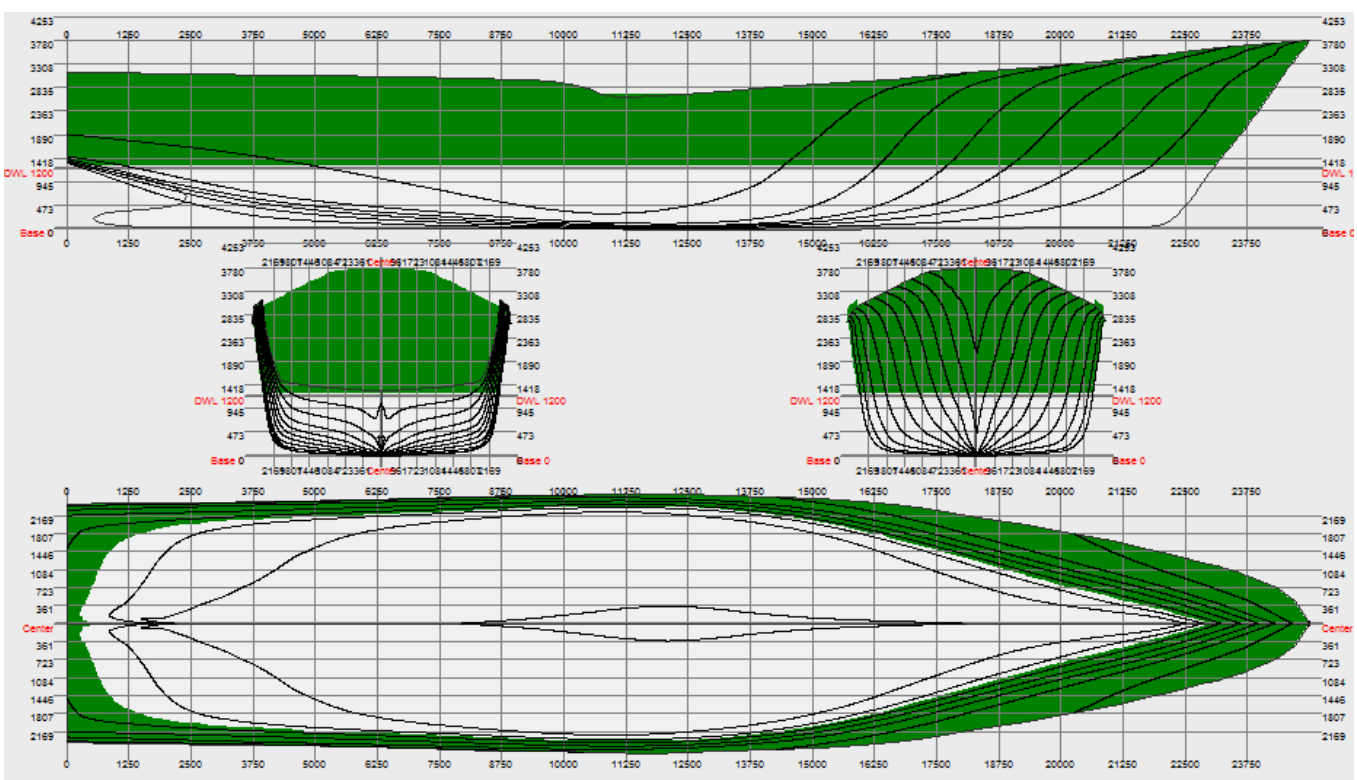

Gambar 1. Lines plan kapal Kapal Tanawangko 30 GT

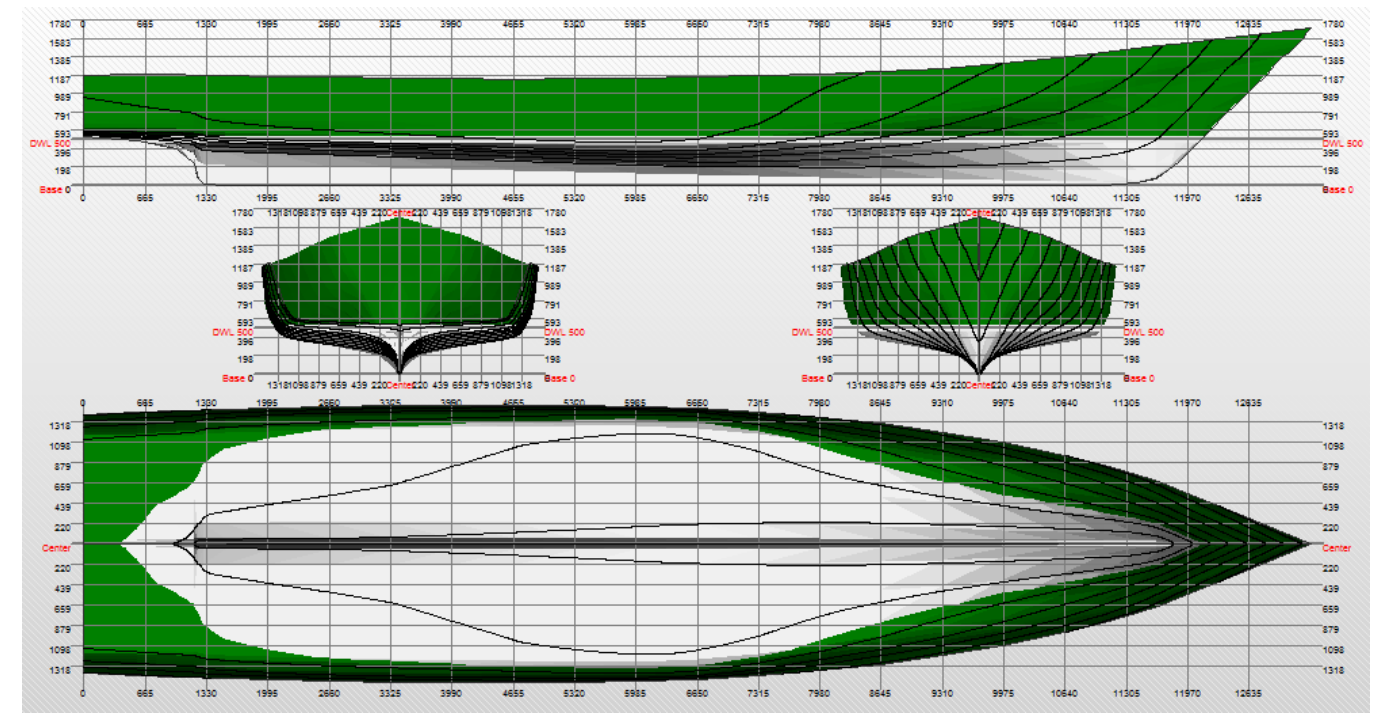

Gambar 2. Lines plan Kapal Tanawangko 5 GT 
Tabel 2. Dimensi utama kapal model

\begin{tabular}{lcccccc}
\hline $\begin{array}{l}\text { Nama } \\
\text { Kapal }\end{array}$ & LOA $(\mathrm{cm})$ & $\mathrm{B}(\mathrm{cm})$ & $\mathrm{D}(\mathrm{cm})$ & $\mathrm{L} / \mathrm{B}(\mathrm{cm})$ & $\mathrm{L} / \mathrm{D}(\mathrm{cm})$ & $\mathrm{B} / \mathrm{D}(\mathrm{cm})$ \\
\hline 30 GT & 80 & 16,50 & 5,50 & 4,48 & 14,54 & 3,00 \\
5 GT & 80 & 18,70 & 4,90 & 4,27 & 16,32 & 3,81 \\
\hline Rata-rata & 80 & 17,50 & 5,50 & 4,48 & 15,50 & 3,80 \\
\hline
\end{tabular}

Tabel 2 memperlihatkan bahwa kedua kapal tersebut memiliki ukuran dimensi utama yang berbeda untuk masing-masing kapal. Nilai ratarata LOA untuk kedua kapal model adalah $80 \mathrm{~cm}$. nilai lebar kapal rata-rata sebesar $17,50 \mathrm{~cm}$ dan dalam kapal sebesar $5,50 \mathrm{~cm}$. Nilai perbandingan antar dimensi utama kapal terutama L/D mendapatkan nilai $15,50 \mathrm{~cm}$ di mana untuk kapal 30 GT nilai D lebih kecil dibanding kapal 5 GT, sehingga kapal 30 GT memiliki nilai D yang relatif rendah.

Dalam proses pembuatan model kapal terdapat beberapa langkah yang perlu dilakukan yaitu: ukuran kapal yang telah diukur dimasukkan ke dalam aplikasi (Delftship) dan kemudian dibuat kembali gambarnya. Mengubah skala kapal prototip ke skala kapal model. Gambar yang telah dicetak sesuai dengan skala pada kapal model dipotong. Potongan gambar yang telah dihasilkan, digambar kembali di atas tripleks untuk dijadikan patron. Tripleks kemudian dipotong sesuai dengan cetakan gambar yang ada. Panjang lunas sesuai skala yang ada kemudian diukur pada kayu lalu dipotong dan dibentuk dudukan gadingnya.
Gading yang dibentuk sesuai dengan jumlah section yang telah ditentukan kemudian dipasang pada lunas berdasarkan dudukannya yang disertai penggunaan waterpass untuk menentukan dan mempertahankan keseimbangan gading. Tripleks dipotong selebar $1 \mathrm{~cm}$ untuk dijadikan sebagai bodi kapal dengan panjang yang disesuaikan. Tripleks yang sudah dipotong direkatkan pada gading kapal dengan memakai lem dan tali untuk menahan tripleks pada gading sampai lem mengeras. Setelah pemasangan gading dan bodi kapal selesai, kapal model didempul lalu dibiarkan mengering selama dua hari. Setelah itu dipernis untuk mendapatkan bentuk lambung kapal yang halus. Setelah dipernis, kapal diletakkan di air untuk melihat kestabilannya dengan menggunakan waterpass.

Pengujian stabilitas kapal melalui pendekatan olengan bebas (free rolling test) dapat dilakukan dengan mengapungkan kapal uji pada air yang tenang dan dilakukan dengan memberikan beban pada sisi kapal dan kembalikan beban tersebut pada posisi semula. Hasil uji pada dua kapal model uji diperlihatkan pada Gbr. 3 .

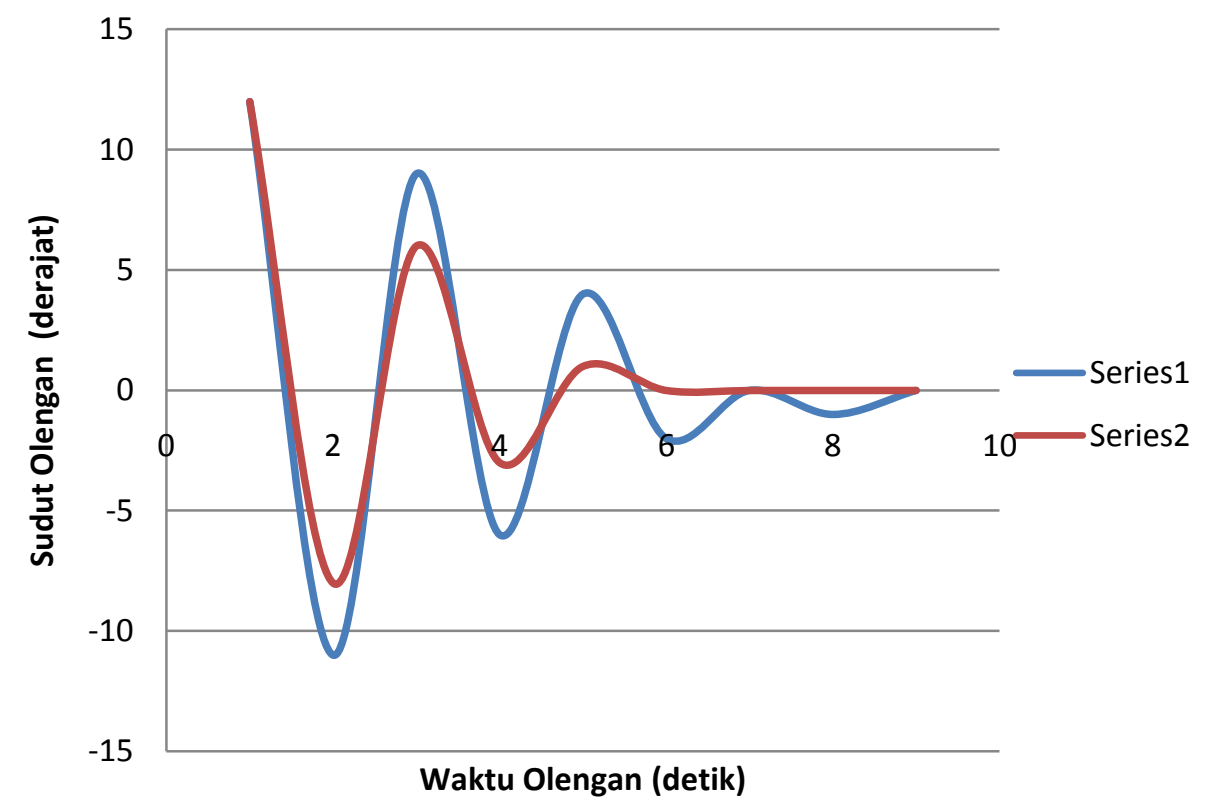

Gambar 3. Grafik roll decay kapal model uji 5 GT (series 2) dan 30 GT (series 1) 
Pengujian stabilitas kapal dengan pendekatan olengan bebas kapal seperti tertera pada Gbr. 3 memperlihatkan bahwa kapal model 5 GT membuat olengan dalam waktu yang pendek hingga kembali pada posisi semula. Dibandingkan dengan olengan bebas yang terjadi pada kapal model tes 30 GT membuat olengan bebas begitu banyak selang waktu yang sama. Pada Gbr. 3 diperlihatkan hubungan antara waktu olengan kapal dengan sudut kemiringan olengan kapal yang dimulai dengan perlakuan sudut olengan kapal sebesar 12 derajat. Dari gambar tersebut terlihat bahwa kapal model uji 5 GT memiliki waktu olengan lebih cepat dibandingkan dengan kapal model uji 30 GT. Berdasarkan teori olengan bebas untuk penentuan roll damping menyatakan olengan kapal yang memiliki periode yang relatif pendek untuk kembali pada posisi semula memiliki kestabilan yang lebih baik dibandingkan dengan kapal yang memiliki periode yang panjang untuk kembali pada posisi semula.

Hasil pengukuran tahanan total kapal yang berukuran 5 dan 30 GT pada kondisi penuh dengan perlakuan empat kondisi trim terlihat pada Gbr. 4\&5. Pada Gbr. 5 nilai tahanan total pada kondisi datar dari kapal model 5 GT memiliki nilai yang lebih kecil pada setiap kecepatan yakni 10.00 g, $10.33 \mathrm{~g}, 14.33 \mathrm{~g}, 14.67 \mathrm{~g}$ secara berturut-turut dibandingkan pada perlakuan trim $1^{0}, 2^{0}$, dan $3^{0}$. Berdasarkan hasil ini diperoleh nilai tahanan pada kondisi datar hanya mencapai nilai $9-11 \%$ dari nilai tahanan total tertinggi pada perlakuan trim $3^{0}$.

Tabel 3.Tahanan total kapal model (5 GT) pada kondisi penuh

\begin{tabular}{ccccc}
\hline $\begin{array}{c}\text { Kecepatan } \\
(\text { Knot })\end{array}$ & $\begin{array}{c}\text { Trim }\left(0^{\circ}\right) \\
(\text { gram })\end{array}$ & $\begin{array}{c}\text { Trim }\left(1^{\circ}\right) \\
(\text { Gram })\end{array}$ & $\begin{array}{c}\text { Trim }\left(2^{\circ}\right) \\
(\text { Gram })\end{array}$ & $\begin{array}{c}\text { Trim }\left(3^{\circ}\right) \\
(\text { Gram })\end{array}$ \\
\hline 0.44 & 10.00 & 63.33 & 68.67 & 100.33 \\
0.50 & 10.33 & 69.67 & 94.33 & 128.33 \\
0.58 & 14.33 & 73.33 & 98.33 & 136.33 \\
0.70 & 14.67 & 78.00 & 104.33 & 148.33 \\
\hline
\end{tabular}

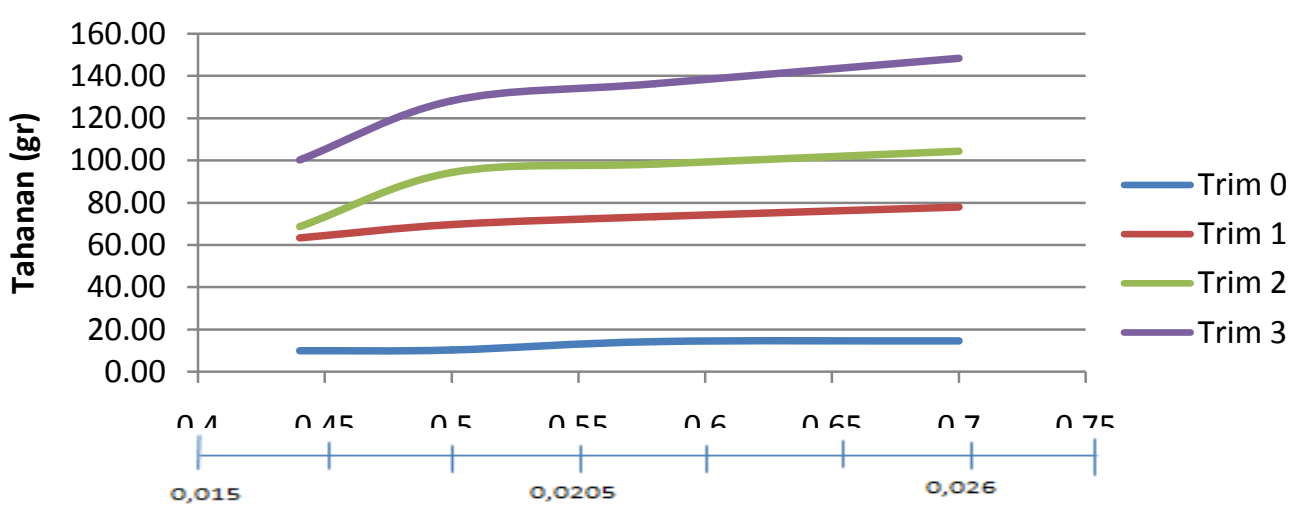

Kecepatan (knot) / Fn

Gambar 4. Nilai tahanan total kapal model 5 GT dengan kondisi penuh

Tabel 4. Tahanan total kapal model (30 GT) pada kondisi penuh

\begin{tabular}{ccccc}
\hline $\begin{array}{c}\text { Kecepatan } \\
(\text { Knot })\end{array}$ & $\begin{array}{c}\text { Trim }\left(0^{\circ}\right) \\
(\text { gram })\end{array}$ & $\begin{array}{c}\text { Trim }\left(1^{\circ}\right) \\
(\text { Gram })\end{array}$ & $\begin{array}{c}\text { Trim }\left(2^{\circ}\right) \\
(\text { Gram })\end{array}$ & $\begin{array}{c}\text { Trim }\left(3^{\circ}\right) \\
(\text { Gram })\end{array}$ \\
\hline 0.44 & 5.00 & 20.00 & 66.67 & 98.67 \\
0.50 & 7.67 & 29.00 & 77.33 & 99.67 \\
0.58 & 11.00 & 38.00 & 82.67 & 101.33 \\
0.70 & 13.33 & 45.33 & 84.00 & 105.00 \\
\hline
\end{tabular}




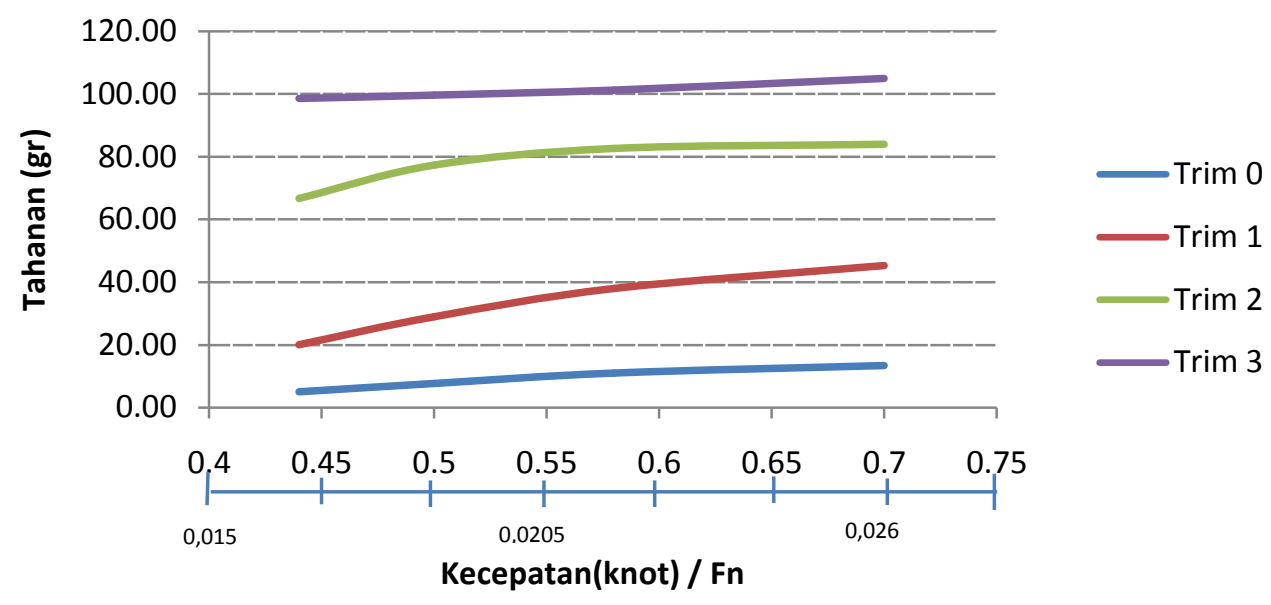

Gambar 5. Nilai tahanan total kapal model 30 GT pada kondisi penuh

Pada Gbr. 5 kondisi kapal model 30 GT dalam kondisi datar memiliki nilai tahanan yang yang lebih rendah (secara berurutan $5.00 \mathrm{~g}, 7.67 \mathrm{~g}$, $11.00 \mathrm{~g}$ dan $13.33 \mathrm{~g}$ ) dari pada nilai tahanan pada perlakuan trim $1^{0}$ hingga $3^{0}$. Nilai tahanan pada trim $2^{0}$ dan $3^{0}$ menunjukkan perbedaan yang sangat signifikan dari nilai tahanan pada kondisi datar dan pada perlakuan trim $1^{0}$. Berdasarkan hasil yang didapat nilai tahanan pada kondisi datar hanya mencapai $5-13 \%$ dari nilai tahanan yang diperoleh pada perlakuan trim $3^{0}$.

\section{KESIMPULAN}

Berdasarkan hasil dan analisis di atas, maka ditarik beberapa kesimpulan seperti di bawah ini: Stabilitas kapal dari kedua model untuk 5 dan 30 GT melalui pendekatan olengan bebas ditemukan bahwa kapal model 5 GT relatif lebih stabil dari pada 30 GT. Ukuran kapal yang ada di galangan kapal Desa Tanawangko berbeda-beda yakni 13,30 $\mathrm{m}$ dan $25 \mathrm{~m}$. Kapal model 5 GT memiliki nilai tahanan total lebih besar oleh karena bentuk bodi kapal dan lambung kapal yang berbentuk gemuk, kapal model ukuran 30 GT memiliki nilai tahanan yang lebih kecil oleh karena bentuk badan dan lambung kapal berbentuk langsing. Nilai tahanan total pada kapal model 5 GT dan 4 trim pada kondisi kapal muatan penuh adalah $148.33 \mathrm{~g}$. Kapal model 5 GT memiliki nilai tahanan lebih besar dibandingkan dengan kapal model 30 GT

\section{DAFTAR PUSTAKA}

Ayodhyoa, A.U. 1972. Fishing Boat. Corespondence Course Centre IPB, Bogor.

Harvald. 1992. Tahanan dan Propulsi Kapal. Airlangga University Press, Surabaya

Masengi. K.W.A., Takeda, K. Ueno, HV Dien, IF Mandagi dan I.Y. Paransa. 2000. International Symposium on Fisheries Science in Tropical area, Proceeding of JSPSDGHE.

Pasaribu, B.P. 1985. Prosiding Seminar Pengembangan Kapal Ikan di Indonesia dalam Rangka Implementasi Wawasan Nusantara, 24 November 1984. Institut Pertanian Bogor, Bogor. 